\title{
Lumbar Disc Herniation in Pediatric
}

\author{
Mostafa Abd Elsamea, Mohamed Shaban, Ahmed Taha*, Samer Elshora \\ Neurosurgery, Orthopedic Department, Faculty of Medicine (Damietta), Al-Azhar University, Egypt \\ Email: *ahmdth231@gmail.com
}

How to cite this paper: Elsamea, M.A., Shaban, M., Taha, A. and Elshora, S. (2018) Lumbar Disc Herniation in Pediatric. Open Journal of Modern Neurosurgery, 8, 233-238.

https://doi.org/10.4236/ojmn.2018.82019

Received: March 17, 2018

Accepted: April 23, 2018

Published: April 26, 2018

Copyright (C) 2018 by authors and Scientific Research Publishing Inc. This work is licensed under the Creative Commons Attribution International License (CC BY 4.0).

http://creativecommons.org/licenses/by/4.0/

(c) (i) Open Access

\begin{abstract}
Lumbar disc herniation is a common complaint among adults with degenerated lumbar intervertebral discs, however its incidence in childhood and adolescence is abundant. Findings recommended that pediatric lumbar disc herniation is dissimilar in numerous way from that in adults. It was confirmed that pediatric patients respond to conventional management less than adults, also the consequence of the operation continued to be acceptable for at least 10 years after the first surgery even though it seems to decline somewhat. This retrospective study was undertaken to determine the clinical outcome and the feature of lumbar disc prolapse in pediatric patients. 12 patients younger than 18 years were operated for lumbar disc prolapse in the period from 2012-2016. Patients preoperative data and radiological imaging, operative and postoperative follow up were reviewed. 12 patients were included in this study, 10 were male and 2 females, the average age was 15 years (ranging between 12 - 18 years). The average duration of the symptoms was 11 months. The average follow up was 14 months. All patients had a sciatica prior to surgery, $35 \%$ had motor deficit, and $60 \%$ had parasthesia. Conservative treatment failed in all patients. After surgery and follow up, improvement occurs in about $80 \%$ of patients, ranging from excellent to good, and $20 \%$ of patients with fair outcome. According to Pain Visual Analogue Scale, leg pain reduced from 90 - 30 and back pain from 80 - 35. Conclusion: Pediatric lumbar disc herniation is an uncommon object leading to hospitalization. About $0.1 \%-0.2 \%$ of children and adolescence surgery for lumbar disc herniation in pediatric does not lead to chronic back pain or interfere with physical activity and is related to the excellent short consequence.
\end{abstract}

\section{Keywords}

Children, Lumbar Disc Herniation, Outcome

\section{Introduction}

Lumbar disc herniation is a common disorder among adults with degenerated 
lumbar intervertebral discs. However, its occurrence in childhood and adolescence is much less frequent mostly because children and adolescents tend to have a healthier lumbar spine as compared with adults. Unique physiological natures of children and adolescents endow pediatric lumbar disc herniation with some distinctive features. However, almost all attentions were given to adult lumbar disc herniation with pediatric lumbar disc herniation remaining partially understood. Over the years, the number of studies in this regard was on a rise, which led to an ever increasing understanding of this entity [1].

Low back pain is the most common causes of debility in individuals aged 45 years or younger and imposes a large socioeconomic burden on society [2]. Patients with lumbar disc herniation frequency suffer from symptoms including, pain, radicular symptoms, and weakness, low back pain might to be aggravated by position and drive [3]. The accurate occurrence of lumbar disc herniation in pediatrics is not completely clear. It was stated that it comprise $0.5 \%-6.8 \%$ of entire patients hospitalization for lumbar disc herniation [4] [5]. There have been little described cases of lumbar disc protrusions under the age of ten in literature, and the youngest age reported was 13 months [6]. Overall, less than $10 \%$ of pediatric low back pain cases are owing to disc herniation and it has been described that fewer than half of these cases need surgery [7] [8]. Thus the clinical appearance of these patients has not been well-defined.

Trauma (sport injury) is usually measured as the greatest portable reasons because as many as $30 \%-60 \%$ of children and adolescences with symptoms lumbar disc herniation have a previous history of trauma prior to the beginning of pain [9]. However, more recent studies suggest that instead of being a primary contributory factor, trauma is likely to be an inciting event in the exacerbation of the pre-existing lesion in the discs, e.g. micro-damage, degenerative changes. The second generally recognized cause is genetic factor. Studies have shown that between $13 \%$ and $57 \%$ of pediatrics with LDH have a first-degree relative with the same disorder [10] [11]. Vertebral anomalies such as scoliosis, transitional vertebra (lumbarisation and sacralisation) et al. are known to be associated with LDH in children Clinical appearance of pediatric lumbar disc herniation are normally like those detected in adults, one characteristic feature is that up to $90 \%$ of the patients have a positive straight leg raising test, which can be clarified by the reason that children and adolescence incline to have larger nerve root tightness than adults [12]. Though neurological symptoms such as numbness and weakness are less than in the adult.

\section{Patients and Methods}

The present study was a retrospective analytical study of 12 patients with lumbar disc herniation in pediatrics, who underwent surgery in the period between 2012 and 2016 in the neurosurgery department, Al-Azhar, faculty of medicine (Damietta). Diagnosis of lumbar disc herniation in these patients was performed using MRI of the lumbosacral spine, it is a non invasive methods to evaluate 
lumbar disc herniation and excluding other cause of back pain. Preoperative data, radiological study, postoperative follow up were recorded and reviewed.

\section{Results}

12 patients were included in this study 10 males (83\%), and 2 females (17\%), the age range from $12-18$ years with an average age of 15 years. The average duration of symptoms was 11 months (range between $10-12$ months) and the average follow up period was 14 months (range between 13 - 15 months). Prior to the surgery all the patients has evaluated using the Pain Visual Analogue Scale. All the patients had sciatica (100\%), 35\% had more deficit in the form of weakness and $60 \%$ had parathesia, some of the patients had also tight hamstring (50\%). As regards to the level of lumbar disc herniation, L4-5 was the most common followed by L5-S1 level (Figure 1).

All the patients were subjected to medical treatment and physiotherapy for about four weeks, and the surgery was done after failure of medical treatment.

The operative techniques was done for the patients in the form of discectomy either open or microscopic without laminectomy, laminoplasty or spinal fusions after surgery and follow up period, improvement occur in $80 \%$ of all patients.

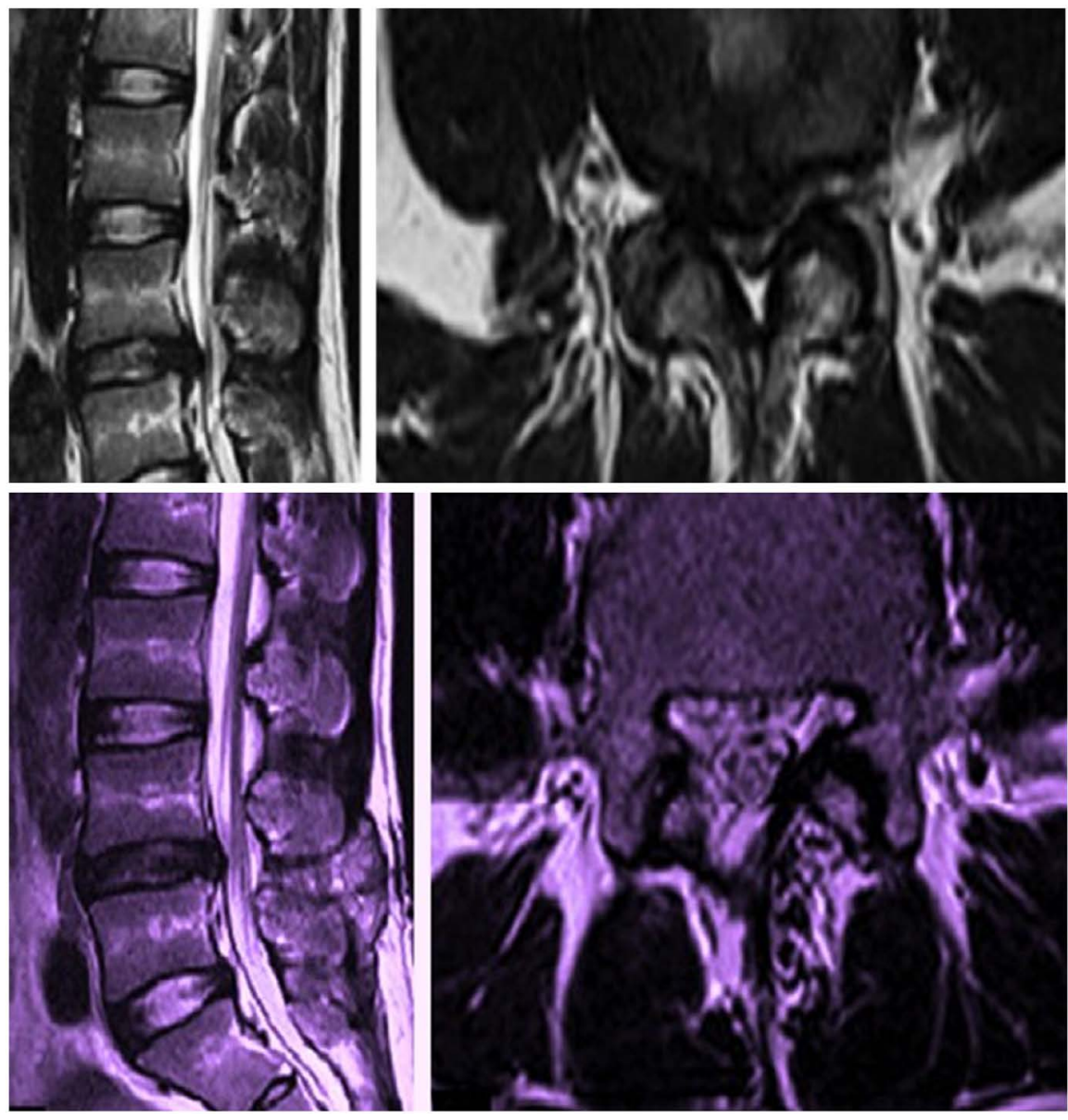

Figure 1. Preoperative and postoperative L4-5 disc. 
Ranging from excellent (45\%) to good (35\%), and fair outcome in (20\%) of patients in the form of residual back pain and some degree of weakness. Regarding to Visual Analogue Scale back pain reduced from 80 - 35, and leg pain from 90 - 30 .

\section{Discussion}

Lumbar disc herniation is a rare disorder in children in 1945, Wahren reported lumbar disc herniation in a 12 years old children [13]. In a report accessible in 1982 of the 9991 discectomies done at many clinic, only $0.5 \%$ were children of the age 16 years and younger [14]. Zitting et al. carried out study with supposed disc herniation in the first 15 years of life, he found an incidence of $0.1 \%-0.2 \%$ and incidence was common in male than female as in our study.

Trauma in the form of sports and lifting a heavy object has been reported to lead symptoms in $30 \%-60 \%$ of pediatric patients.

More than $90 \%$ of children with lumbar disc herniation present with back pain and leg pain in compare with our study $100 \%$ of patients had leg pain and about $90 \%$ had back pain. On examination, all of them have loss of lumbar lordosis and sever limitations of lumbar movements as was the case in our patients and the straight leg raising test is positive in $90 \%$ of cases [15].

MRI is optimal investigations to confirm the reason for lumbar disc prolapsed in children as in case with adults. Non operative treatment in the form of, resting, physiotherapy and non-steriodal anti-inflamatory medications are generally recommended as the first line of management, which seems to be less effective in children than in adults [16] [17]. The indication for surgery in pediatrics is the same as in adults, cauda equine syndrome, progressive neurological deficits, and disability pain affecting the children activity, failure of medical treatment for about 6 weeks, while the surgery is not the first line of treatment in children as it in adults, it should not be delayed as the children have been reported to have good outcome even as long term follow up [14] [18]. Poor outcome have been associated with surgery performed very late following the onset of refractory symptoms. Open discectomy is the procedure performed most often in children as in adults, only the ruptured annulus and the prolapsed disc should be removed.

A total removal of the disc is not advocated, as it may lead to stenosis, alteration at the operated level and degenerative deviation at the contiguous [5]. Fusion should not be performed routinely in children where there is a clear indication of stability like congenital incompetent or sever spondylolithasis.

\section{Conclusion}

Pediatric lumbar disc herniation is an uncommon object leading to hospitalization of about $0.1 \%-0.2 \%$ of children and adolescence. Surgery for lumbar disc herniation in pediatric does not lead chronic back pain or interfere with physical activity and is associated with excellent short term consequence. 


\section{References}

[1] Revuelta, R., De Juambelz, P.P., Fernandez, B. and Flores, J.A. (2000) Lumbar Disc Herniation in a 27-Month-Old Child. Case Report. Journal of Neurosurgery, 92 , 98-100.

[2] Katz, J.N. (2006) Lumbar Disc Disorders and Low-Back Pain: Socioeconomic Factors and Consequences. The Journal of Bone and Joint Surgery. American Volume, 88, 21-24. https://doi.org/10.2106/00004623-200604002-00005

[3] Garcia-Cosamalon, J., del Valle, M.E., Calavia, M.G., Garcia-Suarez, O., Lopez-Muniz, A., Otero, J., et al. (2010) Intervertebral Disc, Sensory Nerves and Neurotrophins: Who Is Who in Discogenic Pain? Journal of Anatomy, 217, 1-15. https://doi.org/10.1111/j.1469-7580.2010.01227.x

[4] Martinez-Lage, J.F., Fernandez Cornejo, V., Lopez, F. and Poza, M. (2003) Lumbar Disc Herniation in Early Childhood: Case Report and Literature Review. Child $s$ Nervous System, 19, 258-260.

[5] Luukkonen, K., Partanen, M. and Vapalaht, M. (1997) Lumbar Disc Herniations in Children: A Long-Term Clinical and Magnetic Resonance Imaging Follow-Up Study. British Journal of Neurosurgery, 11, 280-285. https://doi.org/10.1080/02688699746041

[6] MacGee, E.E. (1968) Protruded Lumbar Disc in a 9-Year-Old Boy. Journal of Pediatrics, 73, 418-419. https://doi.org/10.1016/S0022-3476(68)80122-2

[7] Carey, T.S., Garrett, J., Jackman, A., McLaughlin, C., Fryer, J. and Smucker, D.R. (1995) The Outcomes and Costs of Care for Acute Low Back Pain among Patients Seen by Primary Care Practitioners, Chiropractors, and Orthopedic Surgeons. The North Carolina Back Pain Project. The New England Journal of Medicine, 333, 913-917. https://doi.org/10.1056/NEJM199510053331406

[8] Durham, S.R., Sun, P.P. and Sutton, L.N. (2000) Surgically Treated Lumbar Disc Disease in the Pediatric Population: An Outcome Study. Journal of Neurosurgery, 92, 1-6.

[9] Kurihara, A. and Kataoka, O. (1980) Lumbar Disc Herniation in Children and Adolescents. A Review of 70 Operated Cases and Their Minimum 5-Year Follow-Up Studies. Spine, 5, 443-451. https://doi.org/10.1097/00007632-198009000-00009

[10] Zamani, M.H. and MacEwen, G.D. (1982) Herniation of the Lumbar Disc in Children and Adolescents. Journal of Pediatric Orthopaedics, 2, 528-533. https://doi.org/10.1097/01241398-198212000-00012

[11] DeLuca, P.F., Mason, D.E., Weiand, R., Howard, R. and Bassett, GS. (1994) Excision of Herniated Nucleus Pulposus in Children and Adolescents. Journal of Pediatric Orthopaedics, 14, 318-322. https://doi.org/10.1097/01241398-199405000-00008

[12] Zhang, Y., Sun, Z., Liu, J. and Guo, X. (2008) Advances in Susceptibility Genetics of Intervertebral Degenerative Disc Disease. International Journal of Biological Sciences, 4, 283-290. https://doi.org/10.7150/ijbs.4.283

[13] Zucker, L., Amacher, A.L. and Eltomey, A. (1987) Juvenile Lumbar Discs. Child s Nervous System, 3, 125-127. https://doi.org/10.1007/BF00271141

[14] Frymoyer, J.W., Pope, M.H., Clements, J.H., Wilder, D.G., MacPherson, B. and Ashikaga, T. (1983) Risk Factors in Low-Back Pain. An Epidemiological Survey. The Journal of Bone and Joint Surgery. American Volume, 65, 213-218. https://doi.org/10.2106/00004623-198365020-00010

[15] Shillito, J. (1996) Pediatric Lumbar Disc Surgery: 20 Patients under 15 Years of Age. 
Surgical Neurology, 46, 14-17. https://doi.org/10.1016/0090-3019(96)00035-3

[16] Pfirrmann, C.W., Metzdorf, A., Zanetti, M., Hodler, J and Boos, N. (2001) Magnetic Resonance Classification of Lumbar Intervertebral Disc Degeneration. Spine, 26, 1873-1878. https://doi.org/10.1097/00007632-200109010-00011

[17] Shakeri, M., Yarandi, K.K., Haddadi, K. and Sayyahmelli, S. (2009) Prevalence of Abdominal Aortic Aneurysm by Magnetic Resonance Images (MRI) in Men over 50 Years with Low Back Pain. Rawal Medical Journal, 34, 1-3.

[18] Zitting, P., Rantakallio, P. and Vanharanta, H. (1998) Cumulative Incidence of Lumbar Disc Diseases Leading to Hospitalization up to the Age of 28 Years. Spine, 23, 2337-2343. https://doi.org/10.1097/00007632-199811010-00017 